\title{
TÜRKIYY'DEKİ RÜZGÂR
}

\section{ENERJISII SANTRALLERININ}

GÖRELİ ETKINNLİKLERİNIN VERİ

\author{
Hacettepe Üniversitesi \\ iktisadi ve Idari Bilimler \\ Fakültesi Dergisi, \\ Cilt 34, Sayı 2, 2016 \\ s. $79-96$
}

\section{ZARFLAMA ANALİZİ İLE ÖLÇÜMÜ}

\author{
Mine ÖMÜRGÖNÜLŞEN \\ Doç.Dr., Hacettepe Üniversitesi \\ İktisadi ve İdari Bilimler Fakültesi \\ İşletme Bölümü \\ mergun@hacettepe.edu.tr
}

\section{Tamer EMRE}

Kıdemli Müdür

Pricewaterhouse Coopers

tamer.emre@tr.pwc.com

\section{Kazım Barış ATICI}

Yrd.Doç.Dr., Hacettepe Üniversitesi İktisadi ve İdari Bilimler Fakültesi

İşletme Bölümü

kba@hacettepe.edu.tr

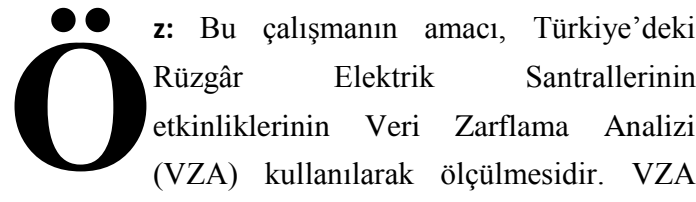
sonuçlarına göre, Türkiye'de faaliyet gösteren rüzgâr santrallerinde genel olarak bir etkinlik problemi vardır. Karar birimlerinin etkinlik seviyelerine göre gruplandırılmasına yarayan bağlam bağımlı VZA yaklaşımı da uygulanarak santraller 7 adet katmana bölünmüştür. Sonuçlar, santrallerin yer aldığı coğrafi bölgeler açısından da yorumlanmaktadır. Ege bölgesi santrallerinin genellikle etkin veya etkine yakın çalıştıkları sonucuna ulaşılmıştır. Analizlerin, ilgili karar vericilere santrallerin performansları hakkında bilgi sunmanın yanı sıra, performansların altında yatan faktörlerin belirlenmesi ve her bir santralin yer aldığ etkinlik katmanını göstermesi açısından enerji sektöründe politika üretmede yol gösterici olacağı düşünülmektedir.

Anahtar Sözcükler: Rüzgâr enerjisi santralleri (RES), göreli etkinlik ölçümü, veri zarflama analizi (VZA), Türkiye. 
THE MEASUREMENT OF

RELATIVE EFFICIENCY OF

WIND POWER PLANTS IN

TURKEY WITH DATA

ENVELOPMENT ANALYSIS

\author{
Hacettepe University \\ Journal of Economics \\ and Administrative \\ Sciences \\ Vol. 34, Issue 2, 2016 \\ pp. $79-96$
}

\author{
Mine ÖMÜRGÖNÜLŞEN \\ Assoc.Prof.Dr., Hacettepe University \\ Faculty of Economics and Administrative \\ Sciences \\ Department of Business Administration \\ mergun@ hacettepe.edu.tr
}

\section{Tamer EMRE}

Electricity Market Services Coordinator

Pricewaterhouse Coopers

tamer.emre@tr.pwc.com

\section{Kazım Barış ATICI}

Assist.Prof.Dr., Hacettepe University

Faculty of Economics and Administrative

Sciences

Department of Business Administratio

kba@hacettepe.edu.tr

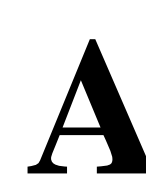

bstract: The purpose of this study is to measure the relative efficiency scores of wind power plants located in Turkey by using Data Envelopment Analysis (DEA). DEA results reveal a high level of inefficiency for the wind power plants operated in Turkey. As well as the standard DEA modeling, context-dependent DEA approach, which enables clustering of units according to their efficiency levels, is also applied to the data set and plants are clustered to 7 layers according to their performance. The results are also interpreted relying on the geographical regions of the plants. Power plants in the Aegean region are identified to operate mostly efficient or close to it. It is believed that the analyses in this study can help related decision makers in policy making via identifying the factors lying behind the performance and giving information about efficiency layers of wind power plants as well as providing insight about the general performance of wind power plants.

Keywords: Wind power plants, relative efficiency measurement, data envelopment analysis (DEA), Turkey. 


\section{GİRIŞ}

Enerji, günümüzde stratejik öneme sahip ve büyük yatırımların yapıldığı önemli bir sektördür. Rüzgâr Elektrik Santralleri (RES) ise, Türkiye'deki yenilenebilir enerji kapasitesi içinde en çok talebin olduğu ve göreli olarak en kolay şekilde lisans, kurulum ve devreye alma işlemlerinin yapılabildiği kapasitedir (Emre, Ömürgönülşen, 2013: 9).

Dünya'da ve Türkiye'de RES'lerin etkinliğinden bahsedilirken yalnızca sayaç değerlerine dayalı yorumlar yapılmakta ve \%40 etkinliği aşan santrallerin "etkin" bulunduğu belirtilmektedir (ewea.org, 2013). Oysa kaynakların doğru ve etkin kullanımı, projenin doğru yapılandırılması gibi konular, bitmiş projelerde söz konusu olamamaktadır. Özellikle kredi kuruluşları ve bankalar, RES projelerinin etkinlik değerlerini kendi yöntemleri ile analiz etmektedir. Ancak onların da kullanabildiği tek veri, sayaç verisi tabanlı etkinlik tahminleridir. Etkinlik ölçümünün sağlıklı yapılamamasının diğer bir nedeni de, santrallere ait verilerin kamuyla paylaşılabilir bir yapıda sunulmamasidır (Emre, 2014: 8).

T.C. Enerji ve Tabii Kaynaklar Bakanlığı Aralık 2014 verilerine göre, Türkiye'de toplam kurulu gücün 69516,4 MW olduğu görülmektedir. Bu kapasitenin önemli bir bölümü, fosil kaynakları (linyit, kömür dizel yakıt vb.) kullanan santraller iken, diğer bir önemli bölümü de, doğal gaz çevrim santralleridir. Rüzgâr Enerjisi, bütün bu kaynaklar arasında \%5,2'lik pay ve 3629,7 MW ile yer almaktadır (tureb.com.tr, 2014). Üretim kaynakları içindeki yeri giderek artan rüzgâr enerjisine yönelik etkinlik çalışmalarının yapılması, yatırımın doğru yönlendirilmesi ve milli servetin değerlendirilmesi anlamında önemli bir başlıktır.

Gerek Dünyada, gerekse Türkiye'de çeşitli sektörlerde etkinlik ölçümünde sıklıkla uygulanan Veri Zarflama Analizi (VZA), ilk kez Charnes, Cooper ve Rhodes (1978) tarafından ortaya atılmıştır. Bu yöntem, benzer girdileri kullanarak benzer çıktıları üreten karar birimlerinin göreli etkinliklerini ölçmeye yarayan parametrik olmayan ve doğrusal programlama temelli bir performans ölçüm yöntemidir. Değerlendirme yapılırken birimlerin kullandığı girdi ve ürettiği çıktı miktarları ele alınır. Amaç, ele alınan girdi ve çıktı değerleri 1şığında bir etkinlik sınırı belirlemek, etkin olan veya etkin olmayan karar birimlerini tespit etmek, etkin olmayan karar birimlerinin bu durumlarının kaynağını analiz etmek ve etkin sınıra ulaşabilecekleri hedef değerleri belirlemektir.

Bu çalışmada, Türkiye Rüzgâr Enerjisi Birliğinin (TÜREB) hazırladığı atlasa göre 2013 yılı Temmuz ayı itibari ile işletmede olan Rüzgâr Enerjisi Santrallerinin (RES) teknik etkinlikleri, Veri Zarflama Analizi (VZA) tekniği kullanılarak ölçülmektedir. Santrallerin teknik etkinlikleri birden fazla girdi ve çıktı faktörünün ele 
alınmasını gerektiren bir problem yapısındadır. Dolayısıyla, en büyük türbine veya en çok türbin sayısına sahip santralin, en etkin santral olduğu veya en çok para kazanan santralin, teknik açıdan en etkin santral olduğu gibi sonuçlara varmak mümkün olmamaktadır. Veri Zarflama Analizi birden fazla faktörün ele alınabilmesi ve etkinliği göreli olarak ölçebilmesi açılarından önemli bulgular sağlayabilecektir. Göreli olarak etkin ve etkin olmayan santrallerin tayini ile kaynakların doğru ve etkin kullanımına ilişkin bir değerlendirme yapmak mümkün olabilecektir. Bugün bu husus, proje firmalarına bağlıdır ve çıktı olarak yalnızca sayaç kapasite kullanım oranı ve kazanılan para kullanılmaktadır.

Çalışma şu şekilde organize edilmiştir: İlk bölümde, Rüzgar Elektrik Santrallerinin etkinliğinin ölçümü (RES) ile ilgili literatür ele alınmaktadır. İkinci bölümde, Veri Zarflama Analizi’nin temel modelleri üzerinde durulmaktadır. Üçüncü bölümde, uygulama metodolojisi (karar birimleri, girdi ve çıktı değişkenleri ile uygulanan VZA tipleri) açıklanmaktadır. Dördüncü bölümde VZA ile elde edilen sonuçlar sunulmakta, beşinci bölümde ise analizin teknik ve yönetsel sonuçları tartışılmaktadır.

\section{LITERATÜR TARAMASI}

Literatürde, RES'lerin etkinliğinin ölçülmesiyle ilgili fazla çalışmaya rastlanmamaktadır. $\mathrm{Bu}$ durumda, hiç süphesiz, RES'lerin, örneğin hidroelektrik santrallerine göre, göreli olarak yeni bir yatırım alanı olmasının etkisi olduğu düşünülmektedir (Emre, Ömürgönülşen, 2013: 15).

Uluslararası literatürde bu çalışmaya 1 şı tutabilecek bazı çalışmalara rastlanmaktadır. Pallabazzer'e göre (2003: 1329-1352), yer seçimi, kapasite (kurulu güç) faktörü için asıl belirleyiciyi oluşturmaktadır. Aynı yıl Korpaas, Holen ve Hildrum, çalışmalarında (2003: 599-606) Norveç Spot Elektrik Piyasası simülasyonu ile RES'lerin spot piyasaya katılımının, sabit fiyattan daha karlı olacağını göstermişlerdir. 2008 yılında RES'lerin hangi ülkede kurulduğu takdirde daha kazançlı çıkacağı konusunda Electre III yöntemi ile çalışan Georgiou vd. (2008: 712-731) çalışması bu alandaki çalışmalardır.

Türkçe literatürde de VZA tekniğinin, enerji ve çevre alanında etkinlik ölçümünde yaygın olarak kullanıldığı görülmektedir. Bilgili vd. (2010) tarafindan Güneybatı ve Batı bölgeleri için yapılan kapasite analizi, Akdağ ve Güler (2010) tarafından yapılan Türkiye'deki RES yatırımlarına ilişkin maliyet analizi ve Güleren ve Demir (2011)'in farklı kanat profillerindeki performans analizlerine ilişkin çalışmaları bu alandaki çalışmalara örnek olarak gösterilebilir. Ayrıca, Baskut vd. (2011), Çeşme'deki santral için yaptıkları çalışmada üretilen enerjiyi değerlendirmişler, sistemin devrede olduğu süre, kapasite kullanım oranlarını dikkate alarak, bazı kapasite 
kullanım oranları için sistem değerlendirmesi yapmışlardır. Türkiye'de RES'lerde etkinlik ölçümü ile ilgili olarak çok fazla çalışma olmadığı görülmektedir. Konuyla ilgili 2013 yılında Marmara Bölgesi için RES Kapasitenin VZA Yöntemi ile göreli etkinlik analizi uygulaması yapıldığı ve etkin olmayan RES'ler belirlendiği bir çalışma mevcuttur (bkz. Emre, Ömürgönülşen, 2013).

\section{VERI ZARFLAMA ANALIZI}

Veri Zarflama Analizi karar birimlerinin birbirlerine göreli etkinliklerinin hesaplanması amacı ile yapılarak birden fazla girdi ve çıktı değişkeninin ele alınmasına olanak vermektedir. Tekniğin uygulanmasında parametrik tekniklerin aksine girdi ve çıktı değişkenleri arasında bir fonksiyonel ilişki kurma amacı güdülmemektedir. Her bir karar birimi için doğrusal programlama modelleri yazılarak çözüm yapılmaktadır.

Temel olarak, Zarflama (Envelopment) ve Çarpan (Multiplier) modelleri olmak üzere iki tip Veri Zarflama Analizi modeli vardır. Birbirlerinin matematiksel olarak duali olan bu modeller aracılığı ile birimlerin etkinlik değerleri elde edilir. Bir karar birimi için her iki tip modelin çözümü de aynı etkinlik değerini vermektedir; ancak optimal karar değişkeni değerleri üzerinden farklı çıkarımlara ulaşılabilmektedir. Zarflama modeli, karar birimleri için etkin sınıra ulaşmak için gerekli olan hedef değerlerin üretilmesini sağlarken birimlerin ağırlıklandırılmış Çıktı/Girdi oranını dikkate alarak yapılan Çarpan tipte modelleme ise karar birimlerinin etkin veya etkin olmama durumlarının kaynağı olan girdi ve çıktıların tespitine yaramaktadır (Cooper vd., 2006; Thanassoulis, 2001).

VZA, girdi ve çıktı odaklı olarak uygulanabilir. Girdi yönlü yaklaşımda belirli bir girdiye karşılık üretilebilecek en yüksek çıktıya göre etkinlik skoru tayin edilmektedir. Çıktı yönlü yaklaşımda, belirli bir çıktıyı elde etmek için kullanılması gereken girdi miktarına göre tespit yapılmaktadır.

$n$ adet karar birimimiz olduğunu varsayalım. Her bir karar birimi $j(j=$ $1,2, \ldots, n) m$ adet girdi kullanıyor ve $s$ adet çıktı üretiyor olsun. Her bir karar biriminin her bir girdi değeri $x_{i j}(i=1,2, \ldots, m)$ ile çıtı değeri ise $y_{r j}(r=1,2, \ldots, s)$ ile gösterilsin. $o$ indisi ise değerlendirme altındaki karar birimini belirtsin. Girdi odaklı Zarflama modeli (1)'de ve bu modelin duali olan Çarpan modeli ise (2)'de verilmiştir.

Minimize $\theta$

Kisitlar:

$$
\begin{array}{ll}
\sum_{j=1}^{n} \lambda_{j} x_{i j} \leq \theta x_{i o} & i=1,2, \ldots, m \\
\sum_{j=1}^{n} \lambda_{j} y_{r j} \geq y_{\text {ro }} & r=1,2, \ldots, s \\
\lambda_{j} \geq 0 & j=1,2, \ldots, n
\end{array}
$$


Model (1)'deki $\theta$ değeri, değerlendirilen karar birimi $o$ 'nun etkinlik skorunu ifade etmektedir. $\lambda_{j}$ değiskenleri ise, modelin diğer karar değişkenlerini oluşturmakta ve değerlendirilen karar biriminin etkin sınırla olan ilişkisini göstermektedir. Modelin çözülmesi sonucu elde edilen optimal $\theta^{*}$ değeri 1'e eşit ise, değerlendirilen karar birimi etkin sınır üzerindedir. 1'den küçük $\theta^{*}$ değeri karar biriminin etkin olmadığının göstergesidir. Modelin çözülmesi sonucu elde edilen $\lambda_{j}$ değerleri ile $x_{i j}$ ve $y_{r j}$ değerleri çarpılıp toplanarak, etkin olmayan bir karar birimi için her girdi ve her çıktı açısından etkin sınıra ulaşma hedef değerleri hesaplanabilir.

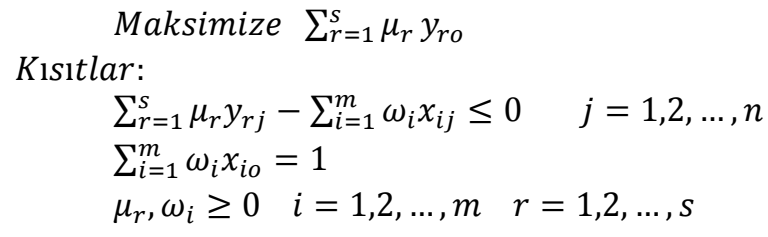

Model (2)'de amaç fonksiyonu değeri karar birimi o 'nun etkinlik skorunu vermektedir ve aynı karar birimleri için model (1) ve (2)'de elde edilen etkinlik skorları aynıdır. Model (2)'deki $\mu$ ve $\omega$ değişkenleri sırasıyla çıktı ve girdi ağırlıklarını temsil etmektedir. Çözüm sonucunda elde edilen ağırlık değerleri ile gerçek değerler çarpılarak her bir çıktı ve girdi için sanal (virtual) ağırlık değeri hesaplanır. Bu değerler, değerlendirilmekte olan karar biriminin güçlü ve zayıf olduğu girdi ve çıktıları göstermektedir. Buradan hareketle birimin etkin veya etkin olmama durumu üzerinde hangi değişkenlerin etkili olduğu üzerinde çıkarımda bulunulabilir.

Yukarıda verilen ve Charnes $v d$. (1978) tarafindan ortaya atılan orijinal VZA modelleri ölçeğe göre sabit getiri (constant returns-to-scale) varsayımını dikkate almaktadır ve CCR Modelleri olarak bilinirler. Bu tip modelleme girdi ve çıktılar arasında oransal bir ilişki varsayılabildiği durumlarda kullanılmaktadır. Girdi ve çıktılar arasında oransal bir ilişkinin öngörülemediği problemler için Banker, Charnes ve Cooper (1984) tarafından ölçeğe göre değişken getirili (variable returns-to-scale) VZA modelleri türetilmiştir. Bunlar, literatürde genellikle BCC Modelleri olarak isimlendirilirler. BCC Modelleri, standart CCR doğrusal programlama modeline $\lambda$ değişkenlerinin toplamını 1'e eşitleyen bir konveksite kısıdının eklenmesi ile oluşturulur (Ulucan, Atıcı, 2010). Bunun dual modeldeki yansıması ise Model (2)'deki ilk kısıt grubunun sol tarafına eklenen bir serbest değişkendir (Cooper vd., 2006).

Birçok çalışmada, karar birimleri içim hem CCR hem de BCC modelleri ile etkinlik skorları elde edilmekte ve yorumlanmaktadır. Bir karar birimi her iki modelde etkin sınırda yer alıyorsa başka bir deyişle etkinlik skorları iki modelde de \% 100 bulunuyorsa bu birim en üretken ölçekte (most productive scale size) faaliyet gösteriyor demektir. BCC etkinlik skorunun CCR etkinlik skoruna oranlanması ile her birim için 
ölçek etkinliği skoru hesaplanabilir. Etkin sınırda yer almayan bir karar biriminin her iki modelde etkinlik skoru eşit ise ölçek etkinliği skoru 1 çıkacaktır. Böyle bir birim için ölçek etkin ancak teknik etkinsiz denebilir. Başka bir deyişle, bu birimin etkinsizliği yanlış ölçekte faaliyet göstermesinden değil, teknik sebeplerledir (Cooper $v d$., 2006).

Veri Zarflama Analizi sonucunda genel olarak karar birimleri etkin ve etkin olmayan birimler olarak iki sınıfa ayrılmaktadır. Bazı durumlarda, etkin olmayan birimlerin kendi aralarında etkinliklerine göre kümelenmesi performansın geliştirilme hedefi açısından faydalı olabilmektedir. Veri Zarflama Analizi ile etkinlik katmanları oluşturarak her bir katmana kendisinden önce gelen katman hedef olarak belirlenebilir. $\mathrm{Bu}$ tip bir analiz, kısa ve uzun vadeli hedefler belirlemek açısından önemlidir. Seiford ve Zhu (2003) tarafindan ortaya atılan bağlam bağımlı (context-dependent) VZA bu amaca yöneliktir. Her aşamada etkin olan birimler, veri setinden çıkarılarak VZA tekrarlanmaktadır ve veri etkinlik katmanlarına bölünmektedir. Böylelikle, en alt katmanda yer alan bir birime daha gerçekçi hedef birimler atanabilmektedir.

\section{METODOLOJİ}

Bu çalışmada, Türkiye Rüzgâr Enerjisi Birliğinin (TÜREB) hazırladı̆̆g atlasa göre, 2013 yılı Temmuz ayı itibari ile işletmede olan tüm Rüzgâr Enerjisi Santrallerinin (RES) (61 adet) teknik etkinlikleri Veri Zarflama Analizi kullanılarak ölçülmektedir. Örneklem olarak seçilen Türkiye'deki RES kapasitesi, Temmuz 2013 itibariyle, şebekeye elektrik sağlayan ve çalışır durumdaki kapasitedir (Emre, 2014: 9). Türkiye'deki en kapsamlı ve kullanıma açık güncel verileri sağlaması nedeniyle TÜREB'in resmi web sitesinde yayımlanan ve Temmuz 2013 verilerini esas alan Türkiye Rüzgâr Enerjisi Atlası, (TÜREB, 2013) bu çalışmada temel alınmıştır. Buna göre, RES'lerin özellikle rüzgârın bol olduğu Ege ve Marmara Bölgeleriyle, Balıkesir, İzmir ve Manisa illerinde, yoğunlaştığı anlaşılmaktadır (Emre, 2014: 25).

Çalışmanın metodu olarak Veri Zarflama Analizi (VZA) seçilmiştir. Bunun nedenlerini, Veri Zarflama Analizi'nde göreli olarak etkinlik ölçümü yapılabilmesi, aynı birim ile ölçülmeyen birden fazla faktörü dikkate alınabilmesi, birimlerin güçlü ve zayıf yanlarının ortaya koyulabilmesi ve bağlam bağımlı (context-dependent) modelleme sayesinde birimlerin etkinlik düzeylerine göre gruplanabilmesine olanak sağlaması ile tekniğin uygulama yaygınlığı ve kolaylı̆ğ olarak sıralayabiliriz. Bu çalışmada, Türkiye'deki RES'lerin ortalama yatırım maliyetleri ile üretim performanslarına göre ortalama kazanç tutarları karşılaştırılarak göreli etkinlikleri, VZA kullanılarak ölçülmektedir. Çalışmanın analiz kısmında, VZA ile ilgili bölüm, MS Excel uygulamaları kullanılarak yapılmaktadır (Emre, 2014: 28). 
Veri Zarflama Analizinin uygulanmasında girdi ve çıktı değişkenlerinin belirlenmesi büyük önem arz etmektedir. Burada, seçilen değişkenler için gerekli verinin ulaşılabilirliğinin yanı sıra, karar vericilerin bu değişkenlerin performans üzerinde gözlemlenebilen ve tartışma götürmez etkisinin olması temel varsayımı göz önüne alınmaktadır. Bu çalışmada, rüzgâr enerjisi sektör uzmanlarından görüş alınarak ve literatürdeki benzer çalışmalardaki değişkenler incelenerek aşağıda sıralanan girdi ve çıktı değişkenleri belirlenmiştir. Belirlenen değişkenlere yönelik olarak, her santral için veri toplanmıştır.

\subsection{Girdi Değişkenleri}

$\mathrm{Bu}$ çalışmada girdi değişkenleri olarak santral kurulum maliyeti, rüzgâr hızı ve rüzgâr kapasite faktörü kullanılmaktadır.

\subsubsection{Santral Kurulum Maliyeti}

İlgili literatür incelendiğinde, VZA ile performans değerlendirmesi yapılırken, santral kurulum maliyetinin bir girdi değişkeni olarak kullanıldığı görülmektedir (Ulucan ve Atıc1, 2010). Bu çalışmada, santrallerin kurulum maliyetleri, kurulu güç ve bağlantı maliyeti üzerinden hesaplanmıştır. Kurulu güce ilişkin maliyet, Avrupa Rüzgâr Enerjisi Birliğgi'nin belirlediği ortalama $1 \mathrm{MW}$ için 1 Milyon Euro maliyet üzerine bağlantı ile ilgili, gerilim seviyesi, hat uzunluğu, iletken kesiti ve sayısı gibi teknik parametreler ayrıntısı ile hesaplanarak bu maliyetler oluşturulmuştur. Çalışma kapsamında 61 santralin yeri tespit edilmiş, elektriksel bağlantı gerilimleri, bağlantı yapılan hat uzunluğu ve kesitleri teker teker tespit edilmiş ve piyasadaki ortalama iletken maliyetleri üzerinden bir hesaplama yapılmıştır.'

\subsubsection{Rüzgâr Hızı}

Rüzgâr hızı, T.C. Enerji ve Tabii Kaynaklar Bakanlığı'na bağlı Yenilenebilir Enerji Genel Müdürlüğü'nün resmi web sitesinde ortalama değerler ile bölge bazında sunulmaktadır. Projeler için şirketler bölgede kendi ölçüm değerlerini kullanmaktadır. $\mathrm{Bu}$ çalışmada santrallerin yerlerine ilişkin rüzgâr değerleri, resmi olarak açıklanmış değerler üzerinden teker teker incelenerek belirlenmiştir.

\subsubsection{Rüzgâr Kapasitesi Faktörü}

Rüzgâr kapasitesi faktörü, Yenilenebilir Enerji Genel Müdürlüğü tarafından yayımlanmış olan verilerdir. Bu faktör, 61 santralin yerleri tespit edilip yayımlanmış veriler üzerinden belirlenmiştir. Kapasite faktörü, bir türbinin değerlendirilmesinde kullanılan en önemli göstergelerden biridir ve sisteminin reelde üretebildiği enerjinin 
nominal güçte üretmesi gereken enerjiye oranı olarak tanımlanır (Mathew, 2006). Kapasite faktörü, türbinin rüzgâr tayfındaki kullanılabilir enerjiyi ne derece etkili kullandığını yansıtmaktadır. Bununla birlikte; kapasite faktörünü etkileyen tek parametre, türbinin üretime girip-çıkma rüzgâr hızları değildir. Aynı zamanda, kullanılan türbin çeşidi ve kurulum yapılacak yerin rüzgâr rejimi de, diğer önemli parametrelerdir (Şenkal, Çetin, 2009: 41).

\section{2. Çıktı Değişkenleri}

Bu çalışmada, çıktı değişkenleri olarak sayaç kapasite kullanım oranı ve yıllık kazanç kullanılmaktadır.

\subsubsection{Sayaç Kapasite Kullanım Oranı}

Öncelikle, 61 santrale ilişkin türbin sayısı ve sayaç sayısı tespit edilmiştir. Bu sayaçların verileri saat bazında tespit edilerek toplanmıştır. Temmuz 2013 öncesi 2 yıllık verilerin teker teker toplanarak lisans gücüne oranlaması ile elde edilen kapasite faktörleri, aylık ortalamalar alınarak kullanılmıştır. Çalışma kapsamında iki milyonun üzerinde veri incelenerek veri madenciliği yapılmıştır. Santrallerin her biri için sezonluk olarak değişen üretim değerleri, saatlik olarak lisans miktarlarına bölünmüş ve her saat için kullanım oranı değerleri hesaplanmıştır. Daha sonra, her santral için tek bir ortalama değere düşürülmüştür. Bu değer, bir santralin etkin çalışması hakkında önemli bir gösterge olarak bilinmektedir.

\subsubsection{Yıllık Kazanç}

RES'ler Yenilenebilir Enerji Destek Mekanizması (YEKDEM)'e katılabilir veya serbest piyasada faaliyet gösterebilirler. YEKDEM, sabit fiyat üzerinden alım garantisidir. Her iki durumda kazançları farklı olmaktadır. 61 santralin seçtikleri işletme koşullarına göre ortalama yıllık kazançları hesaplanmıştır. Destekleme mekanizmasına katılan santrallerin enerjisini satacağı saatlik birim fiyat bellidir. Spot piyasadan enerji satan santrallerin enerjisi ise, her saatte farklı fiyattan muhasebesi yapılmaktadır. Yıllık kazanç değerleri, santrallerin saatlik üretimleri, saatlik fiyatlarıyla çarpılarak elde edilmiştir. Bu veri, santralin kazandığı parayı da bir değişken olarak kullanmak konusunda yardımcı olmaktadır.

61 adet rüzgâr enerjisi santralinin 3 girdi ve 2 çıktı değişkeninden oluşan veri setine Veri Zarflama Analizi çıktı odaklı olarak uygulanmıştır. Burada, analiz için seçilen girdi değişkenlerinin (santral kurulum maliyeti, rüzgâr hızı ve kapasite faktörü) müdahale edilemeyecek faktörler olması, girdi minimizasyonunu öngören girdi odaklı VZA modellerinden ziyade çıktı maksimizasyonu yaklaşımı tercih edilmiştir. Hesaplamalarda, ikinci bölümde bahsedilen iki temel ölçeğe göre getiri yaklaşımı da 
dikkate alınmıştır (CCR ve BCC Modelleri). Bu sayede, santrallerin ölçek etkinlikleri de hesaplanarak optimal ölçekte çalışan santraller belirlenebilmiştir.

Modellemede kullanılan her bir değişken (girdi ve çıktı) için santrallerin tanımlayıcı istatistikleri Tablo 1'de verilmektedir. Santral Kurulum Maliyetleri ile Yıllık Kazanç verileri Türk Lirası ile Rüzgâr Hızı verileri ise metre/saniye ile ölçülmektedir. Kapasite Faktörü ile Kapasite Kullanım Oranı verileri oransal tipte veridir. $\mathrm{Bu}$ oranların paydası nominal güçte üretilmesi gereken enerji düzeyi ile ilişkili olduğu için analizde oransal veri ile ilgili herhangi bir düzeltmeye ihtiyaç duyulmamıştır.

Tablo 1. Verinin Tanımlayıcı İstatistikleri

\begin{tabular}{lcccc}
\hline & Ortalama & Standart Sapma & $\begin{array}{c}\text { Minimum } \\
\text { Değer }\end{array}$ & $\begin{array}{c}\text { Maksimum } \\
\text { Değer }\end{array}$ \\
\hline Girdi Değişkenleri & & & & \\
\hline Santral Kurulum Maliyeti (milyon TL) & 116.1 & 92.9 & 2.5 & 408.4 \\
Rüzgâr Hızı (m/s) & 7.9 & 0.7 & 6.5 & 9.5 \\
Rüzgâr Kapasite Faktörü (\%) & 41.1 & 5.3 & 25.0 & 50.0 \\
\hline Çıktı Değişkenleri & & & & \\
\hline Sayaç Kapasite Kullanım Oranı & 0.3 & 0.1 & 0.2 & 0.5 \\
Y1llık Kazanç (bin TL) & 711.4 & 564.5 & 18.1 & 2446.7 \\
\hline
\end{tabular}

\section{VERİ ZARFLAMA ANALIZİ SONUÇLARI}

Bu bölümde, uygulanan Veri Zarflama Analizi'nin sonuçları ele alınmaktadır. Sonuçlar sunulurken Veri gizliliği sebebiyle santrallerin isimleri sayılar ile kodlanmıştır. Santraller ile ilgili olarak bölge verisi mevcuttur. Değerlendirilen 61 adet santralin büyük çoğunluğu (43 adet) Ege bölgesinde yer almaktadır.

Analizin ilk aşamasında, Model (2)'de verilen çarpan modeli, hem ölçeğe göre değişken getirili, hem de ölçeğe göre sabit getirili olarak uygulanmıştır. Bahsedildiği üzere, iki modelden elde edilen etkinlik skorlarını oranı ölçek etkinliğini vermektedir. Tablo 2, 61 santralin CCR ve BCC modellerindeki etkinlik skorları ile ölçek etkinliği skorlarından oluşmaktadır. BCC Modelinin etkinlik skor ortalaması \%74,3 iken CCR modelindeki ortalama skor \% 69,8 olmuştur. BCC modelinde 8 adet santral etkin sınırda bulunmuştur. CCR modeline göre ise, sadece bir santral (Santral 44) etkin sınırda bulunmuştur. Sonuçlar, genel olarak belirlenen girdi ve çıktılar ışı̆̆ında yüksek oranda bir etkinsizliğe işaret etmektedir. 
Türkiye'deki Rüzgâr Enerjisi Santrallerinin Göreli...| ÖMÜRGÖNÜLŞEN, EMRE, ATICI

Santral 44, her iki modelde de etkin sınırda yer almaktadır. İkinci bölümde bahsedildiği üzere, bu tip karar birimleri için en üretken ölçekte üretim yaptığı çıkarımında bulunulabilmektedir. Bunun dışında her iki modelde de aynı etkinlik skoruna ulaşmış birimler vardır. Bu durum, bu santraller için ölçek etkinliği skorlarının $\% 100$ bulunmasına yol açmaktadır. Bu tip karar birimleri için etkinsizlik faaliyet ölçeğinden ziyade, tamamen teknik nedenlerle oluşmaktadır çıkarımını yapmak mümkündür. Başka bir deyişle, bu santraller belirlenen girdi ve çıktılar ışığında ideal ölçeğe sahip olsa da, göreli olarak diğer santrallerin performansının altında bir performans sergilemektedir (bkz. 9, 31, 49 ve 50 numaralı santraller). Son olarak BCC etkin sinırında yer almasina rağmen CCR etkin sinırında yer almayan santraller de gözlemlenmektedir (örn. 1, 6, 24, 41, 55, 57 ve 58 numaralı santraller). Bu santraller teknik olarak etkin olsalar da, faaliyet ölçeklerinin etkinsizliğinden dolayı tam etkin (fully efficient) değildir (Cooper vd., 2006). 
Tablo 2. Çıktı Odaklı VZA Sonuçları

\begin{tabular}{|c|c|c|c|c|c|c|c|c|c|c|c|}
\hline RES & BCC Skoru & CCR Skoru & $\begin{array}{c}\text { Ölçek } \\
\text { Etkinliği }\end{array}$ & RES & $\begin{array}{c}\text { BCC } \\
\text { Skoru }\end{array}$ & CCR Skoru & $\begin{array}{c}\text { Ölçek } \\
\text { Etkinliği }\end{array}$ & RES & $\begin{array}{l}\text { BCC } \\
\text { Skoru }\end{array}$ & $\begin{array}{c}\text { CCR } \\
\text { Skoru }\end{array}$ & $\begin{array}{c}\text { Ölçek } \\
\text { Etkinliği }\end{array}$ \\
\hline 1 & $100.0 \%$ & $96.3 \%$ & $96.3 \%$ & 22 & $69.2 \%$ & $67.6 \%$ & $97.7 \%$ & 43 & $62.9 \%$ & $62.9 \%$ & $100.0 \%$ \\
\hline 2 & $56.7 \%$ & $56.6 \%$ & $99.7 \%$ & 23 & $60.2 \%$ & $58.8 \%$ & $97.8 \%$ & 44 & $100.0 \%$ & $100.0 \%$ & $100.0 \%$ \\
\hline 3 & $48.7 \%$ & $48.3 \%$ & $99.2 \%$ & 24 & $100.0 \%$ & $76.2 \%$ & $76.2 \%$ & 45 & $67.5 \%$ & $66.4 \%$ & $98.4 \%$ \\
\hline 4 & $78.9 \%$ & $77.3 \%$ & $97.9 \%$ & 25 & $56.3 \%$ & $53.1 \%$ & $94.4 \%$ & 46 & $56.1 \%$ & $56.1 \%$ & $100.0 \%$ \\
\hline 5 & $44.1 \%$ & $40.7 \%$ & $92.2 \%$ & 26 & $63.0 \%$ & $62.0 \%$ & $98.3 \%$ & 47 & $53.4 \%$ & $47.5 \%$ & $88.9 \%$ \\
\hline 6 & $100.0 \%$ & $76.8 \%$ & $76.8 \%$ & 27 & $72.7 \%$ & $70.6 \%$ & $97.1 \%$ & 48 & $63.7 \%$ & $57.4 \%$ & $90.0 \%$ \\
\hline 7 & $77.1 \%$ & $75.4 \%$ & $97.9 \%$ & 28 & $66.8 \%$ & $65.7 \%$ & $98.4 \%$ & 49 & $62.4 \%$ & $62.4 \%$ & $100.0 \%$ \\
\hline 8 & $94.7 \%$ & $73.5 \%$ & $77.7 \%$ & 29 & $50.7 \%$ & $50.1 \%$ & $98.8 \%$ & 50 & $79.3 \%$ & $79.3 \%$ & $100.0 \%$ \\
\hline 9 & $84.8 \%$ & $84.8 \%$ & $100.0 \%$ & 30 & $83.2 \%$ & $78.8 \%$ & $94.8 \%$ & 51 & $62.8 \%$ & $52.9 \%$ & $84.2 \%$ \\
\hline 10 & $78.3 \%$ & $77.9 \%$ & $99.5 \%$ & 31 & $87.2 \%$ & $87.2 \%$ & $100.0 \%$ & 52 & $62.0 \%$ & $57.8 \%$ & $93.2 \%$ \\
\hline 11 & $72.6 \%$ & $68.6 \%$ & $94.5 \%$ & 32 & $82.0 \%$ & $81.4 \%$ & $99.3 \%$ & 53 & $83.6 \%$ & $80.4 \%$ & $96.2 \%$ \\
\hline 12 & $55.9 \%$ & $55.8 \%$ & $99.7 \%$ & 33 & $53.6 \%$ & $50.9 \%$ & $94.9 \%$ & 54 & $73.2 \%$ & $72.3 \%$ & $98.8 \%$ \\
\hline 13 & $98.0 \%$ & $95.9 \%$ & $97.8 \%$ & 34 & $60.0 \%$ & $59.9 \%$ & $99.9 \%$ & 55 & $100.0 \%$ & $77.6 \%$ & $77.6 \%$ \\
\hline 14 & $88.2 \%$ & $75.1 \%$ & $85.1 \%$ & 35 & $74.1 \%$ & $71.2 \%$ & $96.1 \%$ & 56 & $67.7 \%$ & $64.3 \%$ & $95.0 \%$ \\
\hline 15 & $69.9 \%$ & $65.6 \%$ & $93.9 \%$ & 36 & $65.1 \%$ & $64.0 \%$ & $98.4 \%$ & 57 & $100.0 \%$ & $100.0 \%$ & $100.0 \%$ \\
\hline 16 & $69.2 \%$ & $60.5 \%$ & $87.4 \%$ & 37 & $64.7 \%$ & $64.5 \%$ & $99.6 \%$ & 58 & $100.0 \%$ & $100.0 \%$ & $100.0 \%$ \\
\hline 17 & $82.1 \%$ & $79.8 \%$ & $97.1 \%$ & 38 & $72.7 \%$ & $70.1 \%$ & $96.4 \%$ & 59 & $77.3 \%$ & $71.0 \%$ & $91.8 \%$ \\
\hline 18 & $74.6 \%$ & $69.9 \%$ & $93.7 \%$ & 39 & $81.9 \%$ & $80.5 \%$ & $98.4 \%$ & 60 & $79.7 \%$ & $71.9 \%$ & $90.2 \%$ \\
\hline 19 & $87.5 \%$ & $79.5 \%$ & $90.9 \%$ & 40 & $72.5 \%$ & $70.8 \%$ & $97.7 \%$ & 61 & $84.9 \%$ & $76.6 \%$ & $90.2 \%$ \\
\hline 20 & $62.9 \%$ & $60.1 \%$ & $95.5 \%$ & 41 & $100.0 \%$ & $69.7 \%$ & $69.7 \%$ & & & & \\
\hline 21 & $75.0 \%$ & $66.2 \%$ & $88.2 \%$ & 42 & $61.4 \%$ & $60.4 \%$ & $98.4 \%$ & & & & \\
\hline
\end{tabular}


Tablo 3. Çıktılar için Sanal (Virtual) Ağırlık Değerleri

\begin{tabular}{|c|c|c|c|c|c|c|c|c|c|c|c|c|c|c|}
\hline & \multicolumn{2}{|c|}{ BCC Modeli } & \multicolumn{2}{|c|}{ CCR Modeli } & & \multicolumn{2}{|c|}{ BCC Modeli } & \multicolumn{2}{|c|}{ CCR Modeli } & & \multicolumn{2}{|c|}{ BCC Modeli } & \multicolumn{2}{|c|}{ CCR Modeli } \\
\hline & Ciktt 1 & Çıktı 2 & Çוktı 1 & Ciktı 2 & & Çוktı 1 & Çiktı 2 & Çiktı 1 & Çוktı 2 & & Çוktı 1 & Çıktı 2 & Çıktı 1 & Çıktı 2 \\
\hline 1 & $92 \%$ & $8 \%$ & $100 \%$ & $0 \%$ & 22 & $90 \%$ & $10 \%$ & $91 \%$ & $9 \%$ & 43 & $100 \%$ & $0 \%$ & $100 \%$ & $0 \%$ \\
\hline 2 & $88 \%$ & $12 \%$ & $89 \%$ & $11 \%$ & 23 & $94 \%$ & $6 \%$ & $100 \%$ & $0 \%$ & 44 & $0 \%$ & $100 \%$ & $0 \%$ & $100 \%$ \\
\hline 3 & $82 \%$ & $18 \%$ & $83 \%$ & $17 \%$ & 24 & $100 \%$ & $0 \%$ & $100 \%$ & $0 \%$ & 45 & $100 \%$ & $0 \%$ & $100 \%$ & $0 \%$ \\
\hline 4 & $92 \%$ & $8 \%$ & $86 \%$ & $14 \%$ & 25 & $96 \%$ & $4 \%$ & $94 \%$ & $6 \%$ & 46 & $100 \%$ & $0 \%$ & $100 \%$ & $0 \%$ \\
\hline 5 & $100 \%$ & $0 \%$ & $100 \%$ & $0 \%$ & 26 & $73 \%$ & $27 \%$ & $75 \%$ & $25 \%$ & 47 & $100 \%$ & $0 \%$ & $100 \%$ & $0 \%$ \\
\hline 6 & $100 \%$ & $0 \%$ & $100 \%$ & $0 \%$ & 27 & $100 \%$ & $0 \%$ & $100 \%$ & $0 \%$ & 48 & $100 \%$ & $0 \%$ & $100 \%$ & $0 \%$ \\
\hline 7 & $100 \%$ & $0 \%$ & $100 \%$ & $0 \%$ & 28 & $100 \%$ & $0 \%$ & $100 \%$ & $0 \%$ & 49 & $100 \%$ & $0 \%$ & $100 \%$ & $0 \%$ \\
\hline 8 & $0 \%$ & $100 \%$ & $72 \%$ & $28 \%$ & 29 & $100 \%$ & $0 \%$ & $100 \%$ & $0 \%$ & 50 & $100 \%$ & $0 \%$ & $100 \%$ & $0 \%$ \\
\hline 9 & $100 \%$ & $0 \%$ & $100 \%$ & $0 \%$ & 30 & $100 \%$ & $0 \%$ & $100 \%$ & $0 \%$ & 51 & $100 \%$ & $0 \%$ & $100 \%$ & $0 \%$ \\
\hline 10 & $86 \%$ & $14 \%$ & $87 \%$ & $13 \%$ & 31 & $100 \%$ & $0 \%$ & $100 \%$ & $0 \%$ & 52 & $94 \%$ & $6 \%$ & $100 \%$ & $0 \%$ \\
\hline 11 & $95 \%$ & $5 \%$ & $100 \%$ & $0 \%$ & 32 & $100 \%$ & $0 \%$ & $100 \%$ & $0 \%$ & 53 & $91 \%$ & $9 \%$ & $93 \%$ & $7 \%$ \\
\hline 12 & $88 \%$ & $12 \%$ & $89 \%$ & $11 \%$ & 33 & $95 \%$ & $5 \%$ & $100 \%$ & $0 \%$ & 54 & $78 \%$ & $22 \%$ & $80 \%$ & $20 \%$ \\
\hline 13 & $100 \%$ & $0 \%$ & $100 \%$ & $0 \%$ & 34 & $90 \%$ & $10 \%$ & $91 \%$ & $9 \%$ & 55 & $56 \%$ & $44 \%$ & $84 \%$ & $16 \%$ \\
\hline 14 & $100 \%$ & $0 \%$ & $100 \%$ & $0 \%$ & 35 & $100 \%$ & $0 \%$ & $100 \%$ & $0 \%$ & 56 & $100 \%$ & $0 \%$ & $100 \%$ & $0 \%$ \\
\hline 15 & $100 \%$ & $0 \%$ & $100 \%$ & $0 \%$ & 36 & $100 \%$ & $0 \%$ & $100 \%$ & $0 \%$ & 57 & $97 \%$ & $3 \%$ & $100 \%$ & $0 \%$ \\
\hline 16 & $100 \%$ & $0 \%$ & $100 \%$ & $0 \%$ & 37 & $100 \%$ & $0 \%$ & $100 \%$ & $0 \%$ & 58 & $100 \%$ & $0 \%$ & $100 \%$ & $0 \%$ \\
\hline 17 & $100 \%$ & $0 \%$ & $100 \%$ & $0 \%$ & 38 & $93 \%$ & $7 \%$ & $94 \%$ & $6 \%$ & 59 & $94 \%$ & $6 \%$ & $100 \%$ & $0 \%$ \\
\hline 18 & $94 \%$ & $6 \%$ & $100 \%$ & $0 \%$ & 39 & $100 \%$ & $0 \%$ & $100 \%$ & $0 \%$ & 60 & $95 \%$ & $5 \%$ & $91 \%$ & $9 \%$ \\
\hline 19 & $71 \%$ & $29 \%$ & $91 \%$ & $9 \%$ & 40 & $89 \%$ & $11 \%$ & $90 \%$ & $10 \%$ & 61 & $95 \%$ & $5 \%$ & $91 \%$ & $9 \%$ \\
\hline 20 & $100 \%$ & $0 \%$ & $100 \%$ & $0 \%$ & 41 & $100 \%$ & $0 \%$ & $100 \%$ & $0 \%$ & & & & & \\
\hline 21 & $100 \%$ & $0 \%$ & $100 \%$ & $0 \%$ & 42 & $100 \%$ & $0 \%$ & $100 \%$ & $0 \%$ & & & & & \\
\hline
\end{tabular}


Çarpan tipte VZA modelleri, optimal çözümde girdi ve çıktıların aldığı ağırlıklara bakılarak güçlü ve zayıf yönlerin analizine imkan sağlamaktadır. Elde edilen optimal ağırlıklarla girdi ve çıktı değerlerinin çarpımı sonucu sanal (virtual) ağılıklar elde edilir. Bu ağırlıklar, etkinlik veya etkinsizliğin kaynağını işaret etmesi açısından önemlidir. Bu çalışmada, çıktı odaklı VZA modelleri uygulandığından, çıtıların aldığı ağırlık değerlerine bakmak uygun olacaktır. Tablo 3, her iki modelde elde edilen sanal ağırlık değerlerini listelemektedir. Çıktı 1, sayaç kapasite kullanım oranını, Çıktı 2 ise yıllık kazançları temsil etmektedir. Sanal ağırlıklara bakıldığında etkin olmayan santrallerin büyük çoğunluğu için sayaç kapasite kullanım oranı çıktısının daha yüksek ağırlık değerlerine ulaştığı görülmektedir. Buradan yüksek düzeyde etkinsizlik gözlenen sektör için bu etkinsizliklerin altında yatan en önemli faktörün sayaç kapasite kullanım oranı performansının düşüklüğü olduğu sonucuna ulaşılabilir.

Çıktı odaklı standart VZA modellerinin yanı sıra veri setinde yer alan rüzgâr enerjisi santrallerine bağlam bağımlı (context-dependent) VZA modelleri uygulanarak etkinlik katmanları oluşturulmuştur. $\mathrm{Bu}$ analiz her aşamada etkin olan birimler veri setinden çıkartılarak kalanlara VZA uygulanması şeklinde gerçekleştirilmektedir. Santraller etkinlik derecelerine göre kümelenerek her katmandaki etkin santraller belirlenmiştir.

Tablo 4. Etkinlik Katmanları

\begin{tabular}{lccl}
\hline & $\begin{array}{c}\text { Etkin Santral } \\
\text { Sayısı }\end{array}$ & $\begin{array}{c}\text { Ortalama } \\
\text { Etkinlik }\end{array}$ & \multicolumn{1}{c}{ Bölgeler } \\
\hline Katman 1 & 8 & $74.3 \%$ & Ege (4), Marmara (3), Akdeniz \\
Katman 2 & 16 & $84.7 \%$ & Ege (13), Akdeniz (2), Marmara \\
Katman 3 & 15 & $89.2 \%$ & Ege (12), Karadeniz, Akdeniz, Marmara \\
Katman 4 & 8 & $92.3 \%$ & Ege (7), İç Anadolu \\
Katman 5 & 8 & $98.4 \%$ & Ege (4), Akdeniz (2), Marmara, İç Anadolu \\
Katman 6 & 5 & $99.4 \%$ & Ege (3), Akdeniz, Marmara \\
Katman 7 & 1 & $100.0 \%$ & Marmara \\
\hline
\end{tabular}

Tablo 4, her katmandaki etkin santral sayılarını, ortalama etkinliği ve etkin santrallerin bölgelerini göstermektedir. $\mathrm{Bu}$ aşamadaki analizler yine çıktı odaklı olarak ölçeğe göre değişken getiri varsayımı altında gerçekleştirilmiştir. İkinci bölümde bahsedildiği üzere, ölçeğe göre sabit getirili yaklaşım, girdi ve çıktılar arasında bir oransallık ilişkisinden bahsedilebildiği durumlarda uygulanmaktadır. Bu çalışmadaki girdi çıktılar açısından böyle bir oransallık ilişkisinden bahsetmek çok da mümkün olmadığından bağlam bağımlı VZA kısmında ölçeğe göre değişken getiri varsayımına sahip BCC modelleri kullanılmıştır. 
Yapılan kümelemede 7 adet katmana ulaşılmıştır. Son katmanda santral 47 yer almaktadır. Buna göre, santral 47 en etkin olmayan performansı gösteren karar birimidir. Ortalama etkinlik katmanlar arasında ilerledikçe artmaktadır. Santrallerin çoğunluğu ikinci ve üçüncü katmanlarda yer almıştır. Ege bölgesindeki santraller her katmanda yer almaktadır. Veri setindeki santrallerin çoğunluğunun Ege bölgesinde yer alması dolayısıyla bu sonuç normal karşılanabilir. Ancak, Ege bölgesinde yer alan santrallerin büyük çoğunluğunun ilk üç katmanda yer aldığ gerçeği de göz ardı edilmemelidir. En etkin santral olan 44 numaralı santral ile en etkinsiz santral olan 47 numaralı santralin her ikisinin de Marmara bölgesinde yer alması ilgi çekici bir bulgudur.

\section{SONUÇ VE DEĞERLENDİRME}

Rüzgâr enerjisi, halen üzerine en çok yatırım yapılan, en popüler, en fazla istihdam yaratan ve kapasite olarak en hacimli yenilenebilir enerji türüdür. Rüzgâr enerjisi ile ilgili güncel verileri, Dünya, Avrupa ve Türkiye ile ilgili istatistikleri ve tecrübeleri inceledikçe RES'lere ait etkinlik değerlerinin çok fazla irdelenmediği görülmektedir. Kaynağının değiş̧ken yapıda olması, bu tip santrallerin tam kapasite (24 saat) çalışmasına engel olmaktadır. Her bir RES için seçilen alanın rüzgâr kapasite faktörü, rüzgârın esiş hızı, şebekeye uzaklığı birbirinden farklıdır. İletim veya dağıtım şebekesine bağlantı, bağlantıda havai hat veya yer altı kablosu kullanımı, türbin tipi, gücü, sayısı, türbinlerin birbirine uzaklığı, markası vb. değişebilecek faktörler, aslında RES kapasitesinin etkinliğinde rol oynayan faktörler olarak ele alınabilir (Emre, 2014: 22). Santrallerin etkin çalışması üzerinde çok sayıda faktörün etkili olduğu düşünüldüğünde, bu santrallerin performans ölçümünün de çok boyutlu olması gerekmektedir. Veri Zarflama Analizi performans ölçümünde birden fazla girdi ve çıktı değişkeni ele alınarak göreli değerlendirme yapılmasına izin vermesi sebebi ile RES performans ölçümü için uygun bir araç olabilmektedir. Veri Zarflama Analizi’nden elde edilecek performans sonuçları, ilgili karar vericilere analitik bir değerlendirme ve politika üretme imkânı sağlayabilecektir. Bu çalışmada, Türkiye'de işletmede olan 61 adet Rüzgâr Elektrik Santrali için Veri Zarflama Analizi gerçekleştirilmektedir ve bu açıdan öncü bir çalışmadır. Türkiye'deki RES'lerin etkinliğinin ölçülmesi, özellikle enerji alanında yapılacak olan yatırımların doğru yönlendirilmesi bakımından önem arz etmektedir. Veri Zarflama Analizi etkin ve etkin olmayan santralleri ortaya koymasının yanı sıra, etkinsizliğin altında yatan faktörlerin de irdelenmesine imkân sağlaması bakımından da önemlidir. Bunun dışında, tekniğin bir türevi olan bağlam bağımlı modeller sayesinde santrallerin etkinlik seviyelerine göre gruplandırılmasına da imkân sağlamaktadır. Analiz sonuçları mevcut durumun değerlendirmesi ve gelecek için stratejik planlama yapılmasında önemli yol göstericiler olabilecektir. 
Girdi verisi olarak maliyetler, rüzgâr kapasite faktörleri ve rüzgâr hızlarının, çıktı değişkenleri olarak da sayaç kapasite kullanım oranları ile yıllık kazanç miktarlarının kullanıldığ1 ve santral performansına çok boyutlu yaklaşan analiz sonuçlarına göre Türkiye'de faaliyet gösteren rüzgâr santrallerinde genel olarak bir etkinlik problemi vardır. $\mathrm{Bu}$ etkinsizliklerin altında yatan en önemli faktörün sayaç kapasite kullanım oranı performansının düşüklüğü olduğu tespit edilmiştir. Başka bir deyişle, santrallerin etkinsizliğinin altında kapasitenin sayaca yansımaması gerçeği yatmaktadır. Yalnızca, Marmara bölgesinde faaliyet gösteren bir santralin (santral 44) en etkin ölçek büyüklüğünde faaliyet gösterdiği bulunmuştur. Santraller etkinlik seviyelerine göre 7 katmana ayrılmıştır. İlgi çekici bir biçimde en etkin çalışan santral (44) ile en etkinsiz santralin (47) her ikisi de Marmara bölgesinde yer almaktadır. Türkiye'de işletmede olan rüzgâr enerjisi santrallerinin \%70'ini barındıran Ege bölgesinde yer alan santrallerin büyük çoğunluğunun etkin veya etkine yakın çalıştı̆̆ı tespit edilmiştir. Literatürde Bilinebildiği kadarıyla, Türkiye'de faaliyet gösteren tüm rüzgâr enerjisi santrallerinin etkinliği üzerine bir çalışma bulunmamaktadır. Emre ve Ömürgönülşen (2013) Marmara bölgesinde benzer bir çalışma yürütmekte ve bölgedeki santrallerin etkinlikleri üzerine çıkarımlarda bulunmaktadır. Bu çalışma, Marmara Bölgesindeki santrallerin Türkiye genelindeki durumlarına da 1 şı tutarak analiz kapsamını genişletmektedir ve bu konudaki literatürü tamamlayıcı bir rol oynamaktadır.

$\mathrm{Bu}$ çalışmadaki analizlerin, ilgili karar vericilere santrallerin genel performansları hakkında bilgi sunmanın yanı sıra, performansların altında yatan faktörlerin belirlenmesi ve her bir santralin yer aldığı etkinlik katmanını göstermesi açısından politika üretmede yol gösterici olacağı düşünülmektedir. RES performansı tek bir oran ile değerlendirilemeyecek kadar karmaşık bir yapıdadır. Yapılan analizler, VZA tekniğinin bu çok boyutlu problem açısından uygun bir araç olabileceğini göstermesi açısından önem arz etmektedir. Gelecek çalışmalarda, VZA Türkiye'deki diğer yenilenebilir enerji kaynaklarının etkinliğinin ölçümünde kullanılabilir.

\section{NOTLAR}

${ }^{1}$ RES'lerin kurulum maliyetlerinden önemli bir bölümünü de bağlantı maliyetini içermektedir. İletimin yüksek gerilim veya dağıtımın orta gerilim hattına bağlantı, donanımların gerilime karşı dayanımı gereği birbirinden farklı maliyetleri getirmektedir. Bu çalışmada kullanılan hatta uzaklık verisi, YEGM verileri de kullanılarak yaklaşık değerlerden elde edilmiş verilerdir. Teker teker incelenen bağlantı hat kesitleri, yaklaşık birim fiyatlar ile çarpılmış ve yaklaşık bağlantı maliyeti verileri oluşturulmuştur. Santrallerin her birinin bağlantı anlaşmalarının tespit edilmesi, bağlantı mesafelerinin ve gerilimlerinin tespit edilmesi, bu bağlantılara ait hat kesitleri bilgilerine ulaşılması, hat maliyetlerinin piyasadaki firmalar ile görüşülerek ortalama bir fiyata dönüştürülmesi, veri toplama sürecinde uğraşılan zorlu bir konudur. 61 karar birimi için dağıtım şirketleri ve iletim şirketlerinin bölge sorumluları ile temasa geçilmiş, hat kesitleri, kaç tip hat kullanıldı $\breve{g}$, iletken malzemesi vs. birçok veri teker teker elde edilmiştir. Kurulum maliyeti 
verileri, kapasite miktarının bir katsayı ile çarpımı ile elde edilen yaklaşık sonuç ve bağlantı maliyeti için hesaplanan yaklaşık sonucun toplamıdır. Kurulum maliyeti verileri, matematiksel hesaplarda aynen kullanılırken, bu çalışmada ticari sır olabileceği endişesi ile şifrelenmiştir. (Emre, 2014: 52,53).

\section{KAYNAKÇA}

Akdağ, S.A., Ö. Güler (2010), "Evaluation of wind Energy Investment Interest and Electricity Generation Cost Analysis for Turkey”, Applied Energy, 7, 2574-2580.

Banker, R., A. Charnes, W.W. Cooper (1984), "Some Models for Estimating Technical and Scale Inefficiencies in Data Envelopment Analysis", European Journal of Operational Research, 30(9), 1078-1092.

Baskut, Ö., Ö. Özgener, L. Özgener (2011), "Second Law Analysis of wind Turbine Power Plants: Cesme, Izmir Example”, Energy, 36(5), 2535-2542.

Bilgili, M., B. Şahin, E. Şimşek (2010), “Türkiye'nin Güneybatı ve Batı Bölgelerindeki Rüzgâr Enerjisi Potansiyeli”, Isı Bilimi ve Teknik Dergisi, 30(1), 1-12.

Charnes, A., W.W. Cooper, E. Rhodes (1978), "Measuring the Efficiency of Decision Making Units", European Journal of Operational Research, 2, 429-444.

Cooper, W.W., L.M. Seiford, K. Tone (2006), Introduction to Data Envelopment Analysis and Its Uses, New York: Springer.

Emre, T. (2014), “Türkiye'deki Rüzgâr Enerjisi Santrallerinin (RES) Göreli Etkinliklerinin Veri Zarflama Analizi (VZA) ile Ölçümü”, Yayınlanmamış Yüksek Lisans Tezi, Ankara: Hacettepe Üniversitesi Sosyal Bilimler Enstitüsü.

Emre, T., M. Ömürgönülşen (2013), "Marmara Bölgesindeki Rüzgâr Elektrik Santrallerinin Veri Zarflama Yöntemi ile Göreli Etkinlik Analizi”, Verimlilik Dergisi, 2013(4), 7-32.

EWEA European Wind Energy Association Annual Statistics (2013) (http://www.ewea.org/fileadmin/files/library/publications/statistics/EWEA_Annual_Stat istics_2013.pdf)

Georgiou, P., C. Tourkolias, D. Diakoulaki (2008), "A Roadmap for Selecting host Countries of wind Energy Projects in the Framework of the Clean Development Mechanism", Renewable and Sustainable Energy Reviews, 12(3), 712-731.

Güleren, K.M., S. Demir (2011), "Rüzgâr Türbinleri için Düşük Hücum Açılarında Farklı Kanat Profillerinin Performans Analizi”, Isı Bilimi ve Tekniği Dergisi, 31(2), 51-59.

Mathew, S. (2006), Wind Energy Fundamentals, Resource Analysis and Economics, Germany: Springer Berlin Heidelberg Inc.

Pallabazzer, R. (2003), "Parametric Analysis of wind Siting Efficiency", Journal of Wind Engineering and Industrial Aerodynamics, 91, 1329-1352.

Seiford, L.M., J. Zhu (2003), "Context-Dependent data Envelopment Analysis: Measuring Attractiveness and Progress", Omega, 31(5), 397-480.

Şenkal, A., N.S. Çetin (2009), “Türkiye'de Kurulu Olan Büyük Güçlü Rüzgar Santrallerinin Kapasite Faktörlerine Genel Bir Bakış”, Ege Bölgesi Enerji Forumu, 12-13 Ekim 2009, Denizli, 40. 
ÖMÜRGÖNÜLȘEN, EMRE, ATICI | The Measurement of Relative Efficiency of Wind Power...

Thanassoulis, E. (2001), Introduction to The Theory and Application of Data Envelopment Analysis, Dordrecht: Kluwer Academic Publishers.

Türeb (Türkiye Rüzgar Enerjisi Birliği) Resmi Web Sitesi (2014).

Ulucan, A., K.B. Atıcı (2010), "Enerji ve Çevre Konularında Parametrik Olmayan Etkinlik Analizi ve Türkiye Elektrik Sanayii Uygulaması", Hacettepe Üniversitesi İktisadi ve İdari Bilimler Fakültesi Dergisi, 28(1), 173-203.

Hacettepe University Journal of Economics and Administrative Sciences Vol 34, Issue 2, 2016 